\title{
RISK ASSESSMENT KECELAKAAN KERJA PADA PEKERJAAN AIRCRAFT PAINT REMOVAL DI PT. X
}

\section{RISK ASSESSMENT OF ACCIDENT ON AIRCRAFT PAINT REMOVAL ACTIVITIES AT PT. $X$}

\author{
Hesti Fiskalisa Purbayanti, Sho'im Hidayat \\ Departemen Keselamatan dan Kesehatan Kerja \\ Fakultas Kesehatan Masyarakat Universitas Airlangga \\ E-mail: hestifiskalisa@yahoo.com
}

\begin{abstract}
The entire activity involving human factors, machinery, chemicals, and through some work processes had the potential hazard that increased the risk of accidents and health problems. Aircraft paint removal job was a high risk of an accident. The purpose of this research -was to identify hazards, assess pure risks, identify risk control, and assess risks after risk control -were conducted on aircraft paint removal job in PT. X. Type of this research was descriptive research. Primary data retrieval techniques in the study were observational and interview. The subjects of research were 1 PDCA HSE and 4 aircraft paint removal workers. Variable in this study is the hazards, likelihood, severity, risk levels, and risk control. The results of hazard identification obtained 14 risks in Aircraft Paint Removal such as 1 low risk, 2 middle risks and 13 high risks. Risk control by the company showed that there are 13 high risk decrease to 7, 2 middle risks increased to 6 risks, and 1 low risk increased to 3 risks. In conclusion, PTX. has 14 risks, 13 of them included in the high risk category. There was a decrease in risk due to the control carried out by the company into 13 risks and 7 of them included in high risk.
\end{abstract}

Keywords: aircraft paint removal, hazard identification, risk assessment, risk control

\begin{abstract}
ABSTRAK
Seluruh aktivitas yang melibatkan faktor manusia, mesin, bahan kimia serta melalui beberapa proses kerja memiliki potensi bahaya yang berisiko menyebabkan terjadinya kecelakaan kerja dan gangguan kesehatan. Aircraft paint removal merupakan pekerjaan yang berisiko tinggi terjadi kecelakaan kerja. Tujuan dari penelitian ini adalah untuk mengidentifikasi bahaya, melakukan penilaian risiko murni, mengidentifikasi pengendalian risiko, dan melakukan penilaian risiko setelah dilakukan pengendalian pada pekerjaan aircraft paint removal di PT. X. Penelitian ini merupakan penelitian observasional dengan teknik analisis deskriptif. Teknik pengambilan data primer pada penelitian ini adalah observasi dan wawancara. Subjek penelitian adalah 1 PDCA HSE dan 4 pekerja aircraft paint removal. Variabel pada penelitian ini adalah bahaya, likelihood, severity, tingkat risiko, dan pengendalian risiko. Hasil penelitian menunjukkan bahwa 1 risiko termasuk katagori rendah, 2 risiko termasuk katagori sedang, dan 13 risiko dengan katagori tinggi. Pengendalian oleh perusahaan menunjukkan bahwa terdapat 13 risiko dengan katagori tinggi turun menjadi 7 risiko, 2 risiko sedang meningkat menjadi 6 risiko, serta 1 risiko dengan katagori rendah meningkat menjadi 3 risiko. Kesimpulan dari penelitian ini adalah terdapat 14 risiko di PT. X yang mayoritas termasuk dalam kategori risiko tinggi yaitu sebanyak 13 risiko tinggi. Terjadi penurunan risiko karena adanya pengendalian yang dilakukan oleh perusahaan menjadi 13 risiko dan 7 diantaranya termasuk dalam risiko tinggi.
\end{abstract}

Kata kunci: aircraft paint removal, identifikasi bahaya, pengendalian risiko, penilaian risiko

\section{PENDAHULUAN}

Keselamatan dan Kesehatan Kerja (K3) harus dilaksanakan di semua dunia kerja oleh semua orang yang berada di tempat kerja tersebut. Masingmasing orang memerlukan suatu pekerjaan agar dapat memenuhi kebutuhan kehidupan ataupun untuk meningkatkan kebutuhan aktualisasi diri. Pekerjaan yang dilakukan tersebut pasti memiliki potensi bahaya yang dapat menimbulkan risiko untuk terjadi kecelakaan kerja dan gangguan kesehatan. Risiko dan potensi bahaya yang terdapat di tempat kerja tersebut antara lain terjadi karena proses melakukan suatu pekerjaan, penggunaan mesin berteknologi tinggi, alat dan bahan yang digunakan, posisi tubuh yang tidak ergonomis ketika melakukan pekerjaan, perilaku yang tidak aman ketika bekerja, lingkungan kerja yang buruk, serta budaya kerja yang tidak mendukung untuk terciptanya kesehatan dan keselamatan kerja (Kurniawidjaja, 2010). 
Kecelakaan adalah suatu kejadian yang tidak diduga semula dan tidak dikehendaki serta dapat mengakibatkan kerugian baik korban manusia maupun harta benda. Menurut ILO (2013), kecelakaan kerja yang terjadi di tempat kerja setiap tahunnya terdapat lebih dari 250 juta dan lebih dari 160 juta pekerja terkena penyakit yang diakibatkan karena adanya bahaya di tempat kerja, akibat yang paling parah yaitu 1,2 juta pekerja meninggal yang diakibatkan oleh kecelakaan dan sakit di tempat kerja. Menurut data dari BPJS Ketenagakerjaan, terdapat kejadian kecelakaan kerja sebanyak 105.182 kasus sampai dengan akhir tahun 2015 dan 2.375 kasus kecelakaan kerja tersebut mengakibatkan kematian. Penyebab utama kecelakaan kerja tersebut yaitu masih kurangnya kesadaran di kalangan industri maupun masyarakat terhadap pentingnya penerapan K3. Penerapan K3 dianggap sebagai pemborosan biaya, padahal seharusnya penerapan K3 merupakan suatu investasi untuk mencegah agar tidak terjadi suatu kecelakaan kerja (BPJS Ketenagakerjaan, 2015).

Peningkatan pada pengguna jasa transportasi udara di Indonesia terus terjadi. Peningkatan tersebut terjadi baik pada penerbangan domestik maupun internasional sebesar rata-rata $12,5 \%$ setiap tahunnya (BPS, 2014). Keselamatan merupakan prioritas utama dalam dunia penerbangan karena jika suatu kecelakaan sudah terjadi, hal tersebut tidak hanya menimbulkan korban jiwa namun dampak lain yang ditimbulkan adalah pihak maskapai akan memperoleh citra buruk dan dapat berakibat berkurangnya kepercayaan masyarakat untuk kembali menggunakan jasa maskapai tersebut.

Keselamatan penerbangan tidak hanya ketika pesawat tersebut di udara, tetapi harus dimulai sejak pesawat udara berada di darat ketika mendapatkan perawatan. Aircraft maintenance merupakan bagian dari industri penerbangan yang sangat penting untuk menjaga keselamatan penerbangan (Tony, 2013). Perawatan darat pesawat udara tersebut dilakukan oleh industri aircraft maintenance yang yaitu basic maintenance yang terdiri dari perawatan pesawat yang bersifat ringan sampai berat. Selain basic maintenance, terdapat aktivitas line maintenance yang bertugas untuk melakukan pemeriksaan ringan pada pesawat yang akan terbang dan yang sudah mendarat ketika pesawat udara sudah berada di apron seperti before departure check, re-fueling (pengisian ulang bahan bakar). Salah satu aktivitas dari industri aircraft maintenance yang terdapat di basic maintenance adalah aircraft painting yaitu pekerjaan yang bertugas untuk melakukan pengecatan pada seluruh eksterior pesawat udara. Pekerjaan aircraft painting memiliki beberapa tahapan pekerjaan yang salah satunya adalah aircraft paint removal. Aircraft paint removal merupakan proses penghapusan cat lama pada bagian eksterior pesawat yang akan dilakukan pengecatan ulang. Pekerjaan aircraft paint removal tersebut memiliki beberapa potensi bahaya yang dapat menyebabkan terjadinya risiko kecelakaan kerja seperti terjatuh dari ketinggian yang bisa menyebabkan luka serta patah tulang pada anggota tubuh, terbentur bagian dari pesawat yang tajam sehingga dapat mengakibatkan luka memar serta luka robek. Bahan kimia yang digunakan pada aktivitas aircraft paint removal tersebut mengandung B3 yang dapat menyebabkan iritasi kulit apabila terjadi kontak dengan kulit, iritasi mata yang hingga dapat menyebabkan kebutaan apabila kontak dengan mata, serta iritasi saluran pernapasan apabila terhirup. Beberapa bahan kimia yang digunakan untuk proses aircraft paint removal tersebut ada yang bersifat flammable (mudah terbakar).

Sesuai dengan yang disebutkan dalam UndangUndang Republik Indonesia No. 13 tahun 2003 tentang Ketenagakerjaan pasal 86 ayat 1 bahwa setiap pekerja/buruh mempunyai hak untuk memperoleh perlindungan atas Keselamatan dan Kesehatan Kerja, moral dan kesusilaan, serta perlakuan yang sesuai dengan harkat dan martabat manusia serta nilai-nilai agama. Berdasarkan Undang-Undang tersebut, setiap tenaga kerja perlu dijamin keselamatannya karena tenaga kerja merupakan aset yang utama bagi sebuah perusahaan. Tenaga kerja memiliki peranan yang penting dalam proses produksi karena alat-alat produksi juga tidak akan berjalan tanpa adanya dukungan dari tenaga kerja sebagai faktor sumber daya manusia.

Setiap tenaga kerja merupakan aset utama bagi sebuah perusahaan sehingga harus dijamin keselamatannya. Tenaga kerja memiliki peranan yang penting dalam proses produksi karena alat-alat produksi juga tidak dapat berjalan tanpa adanya dukungan dari tenaga kerja sebagai faktor sumber daya manusia. Potensi bahaya yang ada di tempat kerja jika tidak dikendalikan maka dapat berisiko untuk menimbulkan terjadinya kecelakaan kerja. Hal yang dapat dilakukan untuk meminimalisasi risiko kecelakaan kerja tersebut adalah dengan cara melakukan pengelolaan terhadap risiko tersebut.

PT. X merupakan perusahaan yang bergerak di bidang jasa MRO (Maintenance, Repair, dan Overhaul) pesawat udara, komponen, mesin, dan 
produk pendukungnya. Proses kerja di PT. X menggunakan peralatan berteknologi tinggi sehingga yang memiliki potensi bahaya sehingga berisiko untuk menimbulkan kecelakaan kerja. Selain itu, dalam proses produksinya PT. X juga menggunakan bahan berbahaya dan beracun (B3) yang dapat berpotensi menyebabkan ledakan, kebakaran, efek lokal, dan keracunan.

Data sekunder yang didapatkan dari unit K3 PT. X menunjukkan bahwa pada tahun 2014 terdapat 27 kejadian kecelakaan kerja yang bersifat non Lost Time Injury (non-LTI) dan mengalami peningkatan menjadi 62 kejadian pada tahun 2015, serta 2 kejadian kecelakaan kerja yang bersifat Lost Time Injury (LTI) pada tahun 2014 dan menurun menjadi 1 kejadian pada tahun 2015. Tujuan dari penelitian ini adalah untuk mengidentifikasi bahaya, melakukan penilaian risiko murni, mengidentifikasi pengendalian risiko, dan melakukan penilaian risiko setelah dilakukan pengendalian pada pekerjaan aircraft paint removal di PT. X.

\section{METODE}

Penelitian ini merupakan penelitian observasional karena dilakukan pengamatan dan bertujuan untuk memperoleh fakta dari gejala yang ada dan mencari keterangan yang faktual. Menurut jenis analisisnya, penelitian ini termasuk penelitian deskriptif yaitu metode penelitian yang bertujuan memperoleh gambaran tentang suatu keadaan secara objektif. Menurut waktunya termasuk penelitian cross sectional, karena pengamatan terhadap variabel penelitian dilakukan pada periode tertentu saja (Notoatmodjo, 2010).

Subjek dalam penelitian ini adalah 1 orang PDCA HSE aircraft paint removal sebagai informan utama dan 3 orang perwakilan pekerja yang memiliki masa kerja lebih dari 5 tahun untuk memberikan informasi yang mendukung penelitian ini. Variabel dalam penelitian ini yaitu bahaya, likelihood, severity, tingkat risiko, dan pengendalian risiko. Data yang dikumpulkan dalam penelitian ini yaitu data primer dan data sekunder. Data sekunder diperoleh dari data sekunder yang dimiliki oleh perusahaan. Data primer diperoleh dengan menggunakan lembar observasi serta wawancara dengan pihak-pihak yang terkait dengan permasalahan penelitian.

\section{HASIL}

\section{Proses Kerja Aircraft Paint Removal di PT. X}

\section{Masking}

Masking merupakan proses menutup areaarea yang tidak akan dilakukan proses pengecatan ulang. Area-area yang ditutup tersebut yaitu kaca jendela dan kaca cockpit, serta bagian pesawat yang terbuat dari bahan komposit. Area-area tersebut ditutup menggunakan plastik khusus dan tahan terhadap bahan kimia yang digunakan dalam proses pengecatan eksterior pesawat. Plastik tersebut direkatkan dengan menggunakan aluminium tape.

\section{Apply Stripping}

Stripping merupakan proses pengelupasan cat pesawat yang lama dengan menggunakan bahan kimia atau disebut juga sebagai paint stripper yang mengandung hidrogen peroksida. Stripper tersebut diaplikasikan dengan cara disemprotkan menggunakan alat yang disebut dengan spray gun. Setelah diaplikasikan ke area-area yang tidak ditutup menggunakan plastik khusus masking, paint stripper (Turco 6930) tersebut didiamkan selama 3 jam. Residu dari old paint kemudian dibersihkan menggunakan wipper dan selanjutnya dibersihkan lagi menggunakan air panas dengan cara disemprotkan menggunakan alat yang disebut dengan water spray gun pump. Langkah selanjutnya yaitu mengaplikasikan paint stripper yang mengandung soda api (Turco 5351). Pengaplikasian stripper Turco 5351 tersebut tidak menggunakan spray gun, tetapi menggunakan kuas pada area yang masih terdapat old paint (sisa cat lama). Paint stripper yang telah diaplikasikan tersebut didiamkan selama 30 menit.

\section{Sanding}

Sanding merupakan proses mengaplikasikan sander (ampelas) pada area yang terbuat dari bahan selain logam. Tujuan dari sanding adalah untuk menghilangkan efek glossy dari cat lama agar cat baru yang akan diaplikasikan dapat melekat dengan sempurna. Pengelupasan cat menggunakan metode sanding ini tidak sampai menghilangkan seluruh lapisan cat, hanya pada bagian pelapis luarnya saja. 
Protective treatment yang digunakan adalah Allodine 1200. Bahan kimia tersebut bersifat asam dan oxidizer sehingga mudah untuk terbakar. Proses ini dilakukan dengan cara melumurkan Allodine 1200 pada bagian eksterior pesawat yang terbuat dari bahan logam Allodine 1200 yang berfungsi untuk melindungi eksterior pesawat agar terhindar dari korosi.

\section{Hasil Identifikasi Potensi Bahaya pada Pekerjaan Aircraft Paint Removal PT. X}

Identifikasi bahaya diperoleh dari hasil observasi pada aktivitas aircraft paint removal serta wawancara dengan PDCA HSE dan pekerja Aircraft Paint Removal. Hasil dari observasi dan wawancara tersebut menunjukkan terdapat 15 potensi bahaya yang dapat dilihat pada Tabel 1 .

\section{Penilaian Risiko pada Pekerjaan Aircraft Paint Removal PT. X}

Penilaian risiko dilakukan menggunakan analisis tabel semi kuantitatif yaitu dengan cara mengalikan nilai dari kemungkinan untuk terjadinya kecelakaan (likelihood) dengan besarnya dampak yang ditimbulkan apabila kecelakaan tersebut terjadi (severity) yang menghasilkan tingkat risiko. Tabel semi kuantitatif yang digunakan adalah menurut AS/ NZS 4360: 2004 yang ditunjukkan dalam Tabel 2.
Berdasarkan identifikasi potensi bahaya sesuai yang terdapat dalam Tabel 1, didapatkan sebanyak 15 potensi bahaya. Hasil dari identifikasi bahaya tersebut kemudian digunakan sebagai dasar penilaian risiko terhadap setiap risiko yang ada pada aktivitas aircraft paint removal. Penilaian risiko dilakukan dengan melihat kemungkinan kejadian (likehood) dan keparahan dari suatu potensi bahaya tersebut (severity) yang kemudian dituangkan dalam bentuk matriks untuk mengetahui setiap risiko bahaya tersebut termasuk dalam kategori risiko rendah, risiko sedang atau risiko tinggi. Penilaian risiko dilakukan oleh PDCA HSE aircraft paint removal dan satu orang perwakilan dari unit K3. Berdasarkan hasil wawancara dengan perwakilan dari unit K3 tersebut, penilaian risiko dilakukan dengan cara berdiskusi antara perwakilan dari unit K3 dengan PDCA HSE dari unit aircraft paint removal karena PDCA HSE merupakan pihak yang mengerti tentang pekerjaan tersebut. Penilaian risiko dilakukan oleh PDCA HSE dan perwakilan dari unit K3 sehingga hasil dari penilaian risiko ini tidak bersifat subjektif. Hasil dari penilaian risiko menunjukkan bahwa terdapat 16 risiko dengan 1 risiko termasuk kategori rendah, 2 risiko termasuk kategori sedang, dan 13 risiko dengan kategori tinggi. Hasil tersebut secara rinci dapat dilihat pada Tabel 3.

Tabel 1. Identifikasi Bahaya pada Pekerjaan Pekerja Aircraft Paint Removal di PT. X

\begin{tabular}{ll}
\hline \multicolumn{1}{c}{ Aktivitas Pekerja } & \multicolumn{1}{c}{ Potensi Bahaya } \\
\hline Melakukan masking & Cutter tajam dapat melukai tangan pekerja \\
& Jatuh dari ketinggian \\
& Terbentur bagian pesawat yang tajam \\
\hline Apply paint stripper (Turco 6930) & Menghirup Turco 6930 yang mengandung hidrogen peroksida \\
& Kontak stripper dengan kulit \\
\hline Membersihkan sisa old paint dengan air panas & Kontak stripper dengan mata \\
\hline Apply paint stripper (Turco 5351) & Kontak air panas dengan kulit \\
& Menghirup uap stripper yang mengandung basa kuat \\
& Kontak stripper dengan kulit \\
\hline Sanding & Kontak stripper dengan mata \\
\hline Mengaplikasikan protective treatment (Allodine & Getaran yang dihasilkan dari sanding gun \\
1200) & Menghirup debu cat yang diampelas \\
\hline
\end{tabular}


Tabel 2. Matriks Peringkat Risiko

\begin{tabular}{lccccc}
\hline \multirow{2}{*}{ Likelihood } & \multicolumn{5}{c}{ Severity } \\
\cline { 2 - 6 } & $\begin{array}{c}\text { (1) } \\
\text { Insignificant }\end{array}$ & $\begin{array}{c}\text { (2) } \\
\text { Minor }\end{array}$ & $\begin{array}{c}\text { (3) } \\
\text { Moderate }\end{array}$ & $\begin{array}{c}\text { (4) } \\
\text { Major }\end{array}$ & $\begin{array}{c}\text { (5) } \\
\text { Catastrophic }\end{array}$ \\
\hline (1) Rare & 1 & 2 & 3 & 4 & 5 \\
(2) Unlikely & 2 & 4 & 6 & 8 & 10 \\
(3) Possible & 3 & 6 & 9 & 12 & 15 \\
(4) Likely & 4 & 8 & 12 & 16 & 20 \\
(5) Almost Certain & 5 & 10 & 15 & 20 & \\
\hline Sumber: AS/NZS 4360 & & & & & \\
Keterangan tabel : & & & Risiko tinggi & $:$ & \\
Risiko rendah & $:$ & & Risiko ekstrim & $:$ &
\end{tabular}

Tabel 3. Penilaian Risiko pada Pekerjaan Aircraft Paint Removal

\begin{tabular}{|c|c|c|c|c|c|}
\hline \multirow{2}{*}{ Aktivitas Pekerja } & \multirow{2}{*}{ Potensi Bahaya } & \multirow{2}{*}{ Risiko } & \multicolumn{3}{|c|}{ Penilaian Risiko } \\
\hline & & & $\mathbf{L}$ & $\mathbf{S}$ & LOR \\
\hline \multirow[t]{4}{*}{ Melakukan masking } & $\begin{array}{c}\text { Cutter tajam yang } \\
\text { digunakan dapat melukai } \\
\text { tangan pekerja }\end{array}$ & Luka terpotong cutter & 4 & 2 & 8 \\
\hline & \multirow[t]{2}{*}{ Jatuh dari ketinggian } & Luka lecet & 2 & 2 & 4 \\
\hline & & Luka berat (patah tulang) & 2 & 3 & 6 \\
\hline & $\begin{array}{c}\text { Terbentur bagian pesawat } \\
\text { yang tajam }\end{array}$ & Luka robek & 5 & 2 & 10 \\
\hline \multirow{3}{*}{$\begin{array}{l}\text { Apply paint stripper } \\
\text { (Turco 6930) }\end{array}$} & Menghirup uap stripper & Iritasi saluran napas & 5 & 2 & 10 \\
\hline & $\begin{array}{c}\text { Kontak stripper dengan } \\
\text { kulit }\end{array}$ & Dermatitis & 5 & 2 & 10 \\
\hline & $\begin{array}{l}\text { Kontak stripper dengan } \\
\text { mata }\end{array}$ & Iritasi mata & 5 & 2 & 10 \\
\hline $\begin{array}{l}\text { Membersihkan sisa old } \\
\text { paint dengan air panas }\end{array}$ & $\begin{array}{c}\text { Kontak air panas dengan } \\
\text { kulit }\end{array}$ & Luka bakar & 5 & 2 & 10 \\
\hline \multirow{3}{*}{$\begin{array}{l}\text { Apply paint stripper } \\
\text { (Turco 5351) }\end{array}$} & Menghirup uap stripper & Iritasi saluran napas & 5 & 2 & 10 \\
\hline & $\begin{array}{c}\text { Kontak stripper dengan } \\
\text { kulit }\end{array}$ & Dermatitis & 5 & 2 & 10 \\
\hline & $\begin{array}{c}\text { Kontak stripper dengan } \\
\text { mata }\end{array}$ & Iritasi mata & 4 & 3 & 12 \\
\hline \multirow[t]{2}{*}{ Sanding (mengampelas) } & Getaran & Carpal Tunnel Syndrome (CTS) & 5 & 2 & 10 \\
\hline & $\begin{array}{c}\text { Menghirup debu cat yang } \\
\text { dihasilkan dari aktivitas } \\
\text { mengampelas }\end{array}$ & Gangguan pernapasan & 5 & 2 & 10 \\
\hline \multirow[t]{3}{*}{$\begin{array}{l}\text { Apply protective treatment } \\
\text { (Allodine } 1200 \text { ) }\end{array}$} & $\begin{array}{l}\text { Menghirup uap allodine } \\
1200\end{array}$ & Iritasi saluran napas & 5 & 3 & 15 \\
\hline & $\begin{array}{c}\text { Kontak allodine } 1200 \\
\text { dengan kulit }\end{array}$ & Inflamasi & 5 & 2 & 10 \\
\hline & $\begin{array}{l}\text { Kontak allodine } 1200 \\
\text { dengan mata }\end{array}$ & $\begin{array}{c}\text { Iritasi mata, dapat } \\
\text { menyebabkan kerusakan } \\
\text { kornea hingga kebutaan }\end{array}$ & 3 & 4 & 12 \\
\hline
\end{tabular}




\section{Pengendalian Risiko pada PekerjaanAircraft Paint Removal di PT. X}

Informasi tentang pengendalian yang sudah diterapkan oleh PT. X untuk menurunkan tingkat risiko menjadi rendah diperoleh dari hasil wawancara dengan PDCA HSE Aircraft Paint Removal serta dilengkapi dengan observasi oleh peneliti untuk membuktikan bahwa pengendalian tersebut telah dilaksanakan oleh perusahaan. Risiko yang ada pada aktivitas aircraft paint removal tersebut dilakukan penilaian kembali setelah dilakukannya pengendalian risiko oleh PT. X. Hasil dari penilaian risiko setelah dilakukan pengendalian oleh perusahaan menunjukkan bahwa terdapat 3 risiko dengan kategori rendah, 6 risiko dengan kategori sedang, dan 7 risiko dengan kategori tinggi. Hasil dari penilaian risiko tersebut secara rinci dapat dilihat pada tabel 4 .

Tabel 4. Penilaian Risiko Setelah Dilakukan Pengendalian pada Aktivitas Aircraft Paint Removal

\begin{tabular}{|c|c|c|c|c|c|c|}
\hline \multirow{2}{*}{ Aktivitas Pekerja } & \multirow{2}{*}{ Potensi Bahaya } & \multirow{2}{*}{ Risiko } & \multirow{2}{*}{ Pengendalian } & \multicolumn{3}{|c|}{ Penilaian Risiko } \\
\hline & & & & $\mathbf{L}$ & $\mathbf{S}$ & LOR \\
\hline \multirow[t]{4}{*}{ Melakukan masking } & $\begin{array}{c}\text { Cutter tajam yang } \\
\text { digunakan dapat } \\
\text { melukai tangan pekerja }\end{array}$ & $\begin{array}{l}\text { Luka terpotong } \\
\text { cutter }\end{array}$ & Memakai safety knife & 4 & 1 & 4 \\
\hline & \multirow[t]{2}{*}{ Jatuh dari ketinggian } & Luka lecet & Memakai safety belt & 2 & 2 & 4 \\
\hline & & $\begin{array}{l}\text { Luka berat (patah } \\
\text { tulang) }\end{array}$ & Memakai safety belt & 2 & 3 & 6 \\
\hline & $\begin{array}{c}\text { Terbentur bagian } \\
\text { pesawat yang tajam }\end{array}$ & Luka robek & Memakai bump caps & 5 & 2 & 10 \\
\hline \multirow{3}{*}{$\begin{array}{l}\text { Apply paint stripper } \\
\text { (Turco 6930) }\end{array}$} & Menghirup uap stripper & Iritasi saluran napas & Memasang ventilasi & 4 & 2 & 8 \\
\hline & $\begin{array}{c}\text { Kontak stripper dengan } \\
\text { kulit }\end{array}$ & Dermatitis & $\begin{array}{c}\text { Memakai sarung } \\
\text { tangan lateks }\end{array}$ & 5 & 2 & 10 \\
\hline & $\begin{array}{c}\text { Kontak stripper dengan } \\
\text { mata }\end{array}$ & Iritasi mata & Memakai googles & 5 & 2 & 10 \\
\hline $\begin{array}{l}\text { Membersihkan sisa } \\
\text { old paint dengan air } \\
\text { panas }\end{array}$ & $\begin{array}{c}\text { Kontak air panas } \\
\text { dengan kulit }\end{array}$ & Luka bakar & $\begin{array}{c}\text { Memakai paint coat } \\
\text { dan sarung tangan } \\
\text { lateks }\end{array}$ & 3 & 2 & 6 \\
\hline \multirow{3}{*}{$\begin{array}{l}\text { Apply paint stripper } \\
\text { (Turco 5351) }\end{array}$} & Menghirup uap stripper & Iritasi saluran napas & Memasang ventilasi & 4 & 2 & 8 \\
\hline & $\begin{array}{c}\text { Kontak stripper dengan } \\
\text { kulit }\end{array}$ & Dermatitis & $\begin{array}{c}\text { Memakai sarung } \\
\text { tangan lateks }\end{array}$ & 5 & 2 & 10 \\
\hline & $\begin{array}{c}\text { Kontak stripper dengan } \\
\text { mata }\end{array}$ & Iritasi mata & Memakai googles & 4 & 3 & 12 \\
\hline \multirow[t]{2}{*}{$\begin{array}{l}\text { Sanding } \\
\text { (mengampelas) }\end{array}$} & Getaran & $\begin{array}{c}\text { Carpal Tunnel } \\
\text { Syndrome (CTS) }\end{array}$ & $\begin{array}{l}\text { Memakai sarung } \\
\text { tangan khusus } \\
\text { peredam getaran }\end{array}$ & 3 & 2 & 6 \\
\hline & $\begin{array}{l}\text { Menghirup debu cat } \\
\text { yang dihasilkan dari } \\
\text { aktivitas mengampelas }\end{array}$ & $\begin{array}{l}\text { Gangguan } \\
\text { pernapasan }\end{array}$ & Memasang ventilasi & 2 & 2 & 4 \\
\hline \multirow{3}{*}{$\begin{array}{l}\text { Apply protective } \\
\text { treatment (Allodine } \\
1200 \text { ) }\end{array}$} & $\begin{array}{l}\text { Menghirup uap allodine } \\
1200\end{array}$ & Iritasi saluran napas & Memasang ventilasi & 3 & 3 & 9 \\
\hline & $\begin{array}{c}\text { Kontak allodine } 1200 \\
\text { dengan kulit }\end{array}$ & Inflamasi & $\begin{array}{l}\text { Memakai sarung } \\
\text { tangan lateks }\end{array}$ & 5 & 2 & 10 \\
\hline & $\begin{array}{c}\text { Kontak allodine } 1200 \\
\text { dengan mata }\end{array}$ & $\begin{array}{l}\text { Iritasi mata, dapat } \\
\text { menyebabkan } \\
\text { kerusakan kornea } \\
\text { hingga kebutaan }\end{array}$ & Memakai googles & 3 & 4 & 12 \\
\hline
\end{tabular}

Keterangan tabel: L: Likelihood S: Severity $\quad$ LOR: Level of Risk 
Berdasarkan pengendalian yang telah dilakukan oleh PT. X, maka nilai tingkat risiko dapat diturunkan. Rangkuman perbedaan nilai tingkat risiko sebelum dan sesudah dilakukannya pengendalian dapat dilihat pada tabel 5 .

\section{PEMBAHASAN}

\section{Identifikasi Bahaya Pada Pekerjaan Aircraft Paint Removal di PT. X}

Menurut Ramli (2010) identifikasi bahaya merupakan sebuah upaya untuk menjawab potensi bahaya yang ada pada suatu pekerjaan di suatu organisasi atau perusahaan dan bagaimana potensi bahaya tersebut dapat terjadi. PT. X sudah menerapkan manajemen risiko, namun potensi bahaya masih belum diidentifikasikan secara lengkap. Identifikasi bahaya pada pekerjaan Aircraft Paint Removal di PT. X masih dilakukan secara general, belum dilakukan tiap tahapan aktivitas pekerjaannya. Terdapat beberapa potensi bahaya yang belum diidentifikasikan padahal sesuai data kecelakaan yang dimiliki oleh unit K3 di PT. X, potensi bahaya tersebut sudah sampai menyebabkan kecelakaan kerja. Hal yang lain yaitu ada beberapa potensi bahaya yang menghasilkan risiko yang tidak sama, namun diberikan penilaian risiko yang sama.

Tabel 5. Perbedaan Nilai Tingkat Risiko Sebelum dan Sesudah Dilakukan Pengendalian pada Pekerjaan Aircraft Paint Removal di PT. X

\begin{tabular}{|c|c|c|c|c|c|}
\hline No & Risiko & $\begin{array}{l}\text { Nilai Level of Risk } \\
\text { Sebelum Dilakukan } \\
\text { Pengendalian }\end{array}$ & $\begin{array}{l}\text { Kategori } \\
\text { Risiko }\end{array}$ & $\begin{array}{l}\text { Nilai Level of Risk } \\
\text { Setelah Dilakukan } \\
\text { Pengendalian }\end{array}$ & $\begin{array}{l}\text { Kategor } \\
\text { Risiko }\end{array}$ \\
\hline 1. & Luka terpotong cutter & 8 & Sedang & 4 & Rendah \\
\hline 2. & Luka lecet & 4 & Rendah & 4 & Rendah \\
\hline 3. & Luka berat (patah tulang) & 6 & Sedang & 6 & Sedang \\
\hline 4. & Luka robek & 10 & Tinggi & 10 & Tinggi \\
\hline 5. & $\begin{array}{l}\text { Iritasi saluran napas akibat } \\
\text { menghirup Turco } 6930\end{array}$ & 10 & Tinggi & 8 & Sedang \\
\hline 6. & $\begin{array}{l}\text { Dermatitis akibat kontak dengan } \\
\text { Turco } 6930\end{array}$ & 10 & Tinggi & 10 & Tinggi \\
\hline 7. & $\begin{array}{l}\text { Iritasi mata akibat kontak mata } \\
\text { dengan Turco } 6930\end{array}$ & 10 & Tinggi & 10 & Tinggi \\
\hline 8. & Luka bakar & 10 & Tinggi & 6 & Sedang \\
\hline 9. & $\begin{array}{l}\text { Iritasi saluran napas akibat } \\
\text { menghirup Turco } 5351\end{array}$ & 10 & Tinggi & 8 & Sedang \\
\hline 10. & $\begin{array}{l}\text { Dermatitis akibat kontak dengan } \\
\text { Turco } 5351\end{array}$ & 10 & Tinggi & 10 & Tinggi \\
\hline 11. & $\begin{array}{l}\text { Iritasi mata akibat kontak dengan } \\
\text { Turco } 5351\end{array}$ & 12 & Tinggi & 12 & Tinggi \\
\hline 12. & Carpal Tunnel Syndrome (CTS) & 10 & Tinggi & 6 & Sedang \\
\hline 13. & $\begin{array}{l}\text { Gangguan pernapasan akibat } \\
\text { menghirup debu cat yang dihasilkan } \\
\text { dari aktivitas mengampelas }\end{array}$ & 10 & Tinggi & 4 & Rendah \\
\hline 14. & $\begin{array}{l}\text { Iritasi saluran napas karena } \\
\text { menghirup uap allodine } 1200\end{array}$ & 15 & Tinggi & 9 & Sedang \\
\hline 15. & Inflamasi & 10 & Tinggi & 10 & Tinggi \\
\hline 16. & $\begin{array}{l}\text { Iritasi mata, dapat menyebabkan } \\
\text { kerusakan kornea hingga kebutaan }\end{array}$ & 12 & Tinggi & 12 & Tinggi \\
\hline
\end{tabular}




\section{Penilaian Risiko Pada Pekerjaan Aircraft Paint Removal di PT. $X$}

Penilaian risiko merupakan salah satu cara yang dilakukan untuk mengetahui tingkat risiko yang ada pada suatu pekerjaan. Risiko yang telah dinilai tersebut kemudian dikategorikan menjadi risiko dengan kategori rendah, sedang, ataupun tinggi. Hasil dari penilaian risiko tersebut kemudian digunakan sebagai dasar untuk menentukan pengendalian risiko yang tepat sehingga risiko yang ada tersebut dapat diminimalkan hingga hasilnya termasuk kategori rendah. Penilaian risiko dilakukan dengan cara mengalikan probabilitas (likelihood) dengan tingkat keparahan (severity) yang kemudian hasilnya dapat dilihat pada matriks peringkat risiko menurut AS/NZS 4360: 2004 untuk mengetahui tingkat risikonya.

Risiko kategori rendah dalam rentang nilai 1 sampai 4 yaitu meliputi luka lecet akibat jatuh dari ketinggian. Risiko kategori sedang dalam rentang nilai 5 sampai 9 yaitu meliputi luka terpotong cutter dan luka berat akibat jatuh dari ketinggian. Risiko kategori tinggi dalam rentang nilai 10 sampai 16 seperti gangguan pernapasan, dermatitis, iritasi mata, meta carpal syndrome, luka robek karena terbentur bagian pesawat yang tajam, serta luka bakar karena terkena air panas pada kulit.

Severity (keparahan) yang ditimbulkan dari stripper yang digunakan dalam pekerjaan aircraft paint removal ditentukan berdasarkan efek kesehatan yang terdapat dalam Lembar Data Keselamatan Bahan (LDKB) atau disebut sebagai Material Safety Data Sheet (MSDS). Menurut Wiranatha (2014), penggunaan bahan kimia hidrogen peroksida dapat menimbulkan dampak terhadap kesehatan pekerja, sehingga menimbulkan keluhan akibat dari penggunaan bahan kimia tersebut, seperti keluhan pada mata, kulit, serta pernapasan.

Carpal Tunnel Syndrome termasuk dalam kategori risiko tinggi. Carpal Tunnel Syndrome (CTS) merupakan efek dari getaran yang ditimbulkan oleh sanding gun. Hal tersebut sesuai dengan pernyataan Kurniawan dkk (2008), bahwa beberapa faktor diketahui menjadi risiko terhadap terjadinya pada pekerja, seperti gerakan berulang dengan kekuatan, tekanan pada otot, getaran, suhu, postur kerja yang tidak ergonomis dan lain-lain.

\section{Pengendalian Risiko Pada Pekerjaan Aircraft Paint Removal di PT. X}

Pengendalian risiko yang telah diterapkan oleh PT. X mampu menurunkan nilai tingkat risiko yang ada pada pekerjaan aircraft paint removal. Pengendalian risiko yang dilakukan oleh PT. X yaitu berupa penggunaan safety knife, pemberian ventilasi, serta pemakaian Alat Pelindung Diri berupa bumb caps, safety belt, googles, sarung tangan lateks, dan sarung tangan khusus untuk meredam getaran.

Berdasarkan pengendalian yang telah dilakukan oleh PT. X tersebut, masih terdapat 7 risiko yang termasuk dalam kategori tinggi. Risiko yang masih termasuk dalam kategori tinggi tersebut yaitu dermatitis dan iritasi mata karena kontak dengan paint stripper Turco 6930 yang mengandung hidrogen peroksida dan Turco 5351 yang mengandung soda api. Selain itu, risiko yang masih berada dalam kategori tinggi yaitu inflamasi pada kulit akibat kontak dengan protective treatment Allodine 1200 serta iritasi mata yang dapat menyebabkan kerusakan kornea mata dan sampai menyebabkan kebutaan akibat kontak mata dengan protective treatment Allodine 1200.

Risiko yang masih termasuk dalam kategori tinggi tersebut dapat disimpulkan bahwa penyebabnya terdapat tiga sebab yang utama. Penyebab yang pertama yaitu terdapat penyimpangan peraturan yang dilakukan oleh para pekerja Aircraft Paint Removal. Pekerja tidak memakai Alat Pelindung Diri yang diwajibkan oleh perusahaan. Pekerja yang memakai Alat Pelindung Diri berupa sarung tangan peredam getaran tentunya akan memiliki risiko yang lebih kecil untuk terkena carpal tunnel syndrome. Selain itu, pekerja yang memakai Alat Pelindung Diri berupa safety googles dan sarung tangan lateks juga akan memiliki risiko yang lebih kecil untuk kontak langsung dengan paint stripper Turco 6930 dan Turco 5351 serta protective treatment Allodine 1200.

Penyebab yang kedua yaitu belum dilakukan sosialisasi kepada pekerja tentang potensi bahaya yang ada pada pekerjaan mereka. Apabila dilakukan sosialisasi kepada pekerja mengenai bahaya bahanbahan kimia yang digunakan untuk proses aircraft paint removal, maka pekerja akan lebih berhatihati karena sudah memahami potensi bahaya yang 
ada pada pekerjaan mereka dan menggunakan Alat Pelindung Diri yang telah disediakan untuk menghindari kontak dengan bahan-bahan kimia tersebut. Efek terhadap kesehatan pada bahan-bahan kimia tersebut seharusnya disosialisasikan kepada pekerja sesuai yang terdapat dalam Lembar Data Keselamatan Bahan (LDKB) atau disebut juga sebagai Material Safety Data Sheet (MSDS).

Penyebab yang ketiga yaitu tidak memberikan pelindung pada bagian-bagian pesawat yang tajam seperti antena, engine fan cowling door, dan galley door. Pemberian Alat Pelindung Diri berupa bump caps (topi yang terbuat dari bahan keras) masih belum efektif karena tidak semua pekerja memakai Alat Pelindung Diri tersebut. Selain itu, bagian yang lain seperti pelipis mata juga masih belum terlindungi oleh bump caps tersebut. Pemberian pelindung pada bagian-bagian pesawat yang tajam tersebut akan lebih melindungi pekerja dari risiko terbentur.

\section{SIMPULAN}

Berdasarkan hasil dari penilaian risiko diperoleh 14 risiko dengan rincian 1 risiko termasuk kategori rendah, 2 risiko termasuk kategori sedang, dan 13 risiko dengan kategori tinggi. Upaya pengendalian yang dilakukan oleh perusahaan dapat menurunkan tingkat risiko menjadi lebih rendah. Pengendalian risiko yang dilakukan oleh PT. X yaitu berupa penggunaan safety knife, pemberian ventilasi, serta pemakaian Alat Pelindung Diri berupa bumb caps, safety belt, googles, sarung tangan lateks, dan sarung tangan khusus untuk meredam getaran. Hasil dari penilaian risiko setelah dilakukan pengendalian oleh perusahaan menunjukkan bahwa terdapat 13 risiko dengan kategori tinggi turun menjadi 7 risiko, 2 risiko sedang menjadi 6 risiko, serta 1 risiko dengan kategori rendah meningkat menjadi3 risiko.

\section{DAFTAR PUSTAKA}

Australian/New Zealand Standard (AS/NZS) 4360:2004. Risk Management. Joint Technical Commitee OB-007 Risk Management.

Badan Pusat Statistik. Transportasi. Tersedia di: https://www.bps.go.id/Subjek/view/id/17 [diakses tanggal 18 Juli 2017].

BPJS Ketenagakerjaan. Angka Kecelakaan Kerja. Tersedia di http://www.bpjsketenagakerjaan. go.id/berita/2943/Angka-Kasus-KecelakaanKerja-Menurun.html (diakses tanggal 18 Juli 2017].

ILO., 2013. Keselamatan dan Kesehatan Kerja Sarana untuk Produktivitas. Jakarta: ILO.

Kurniawan, B., Jayanti, S., Setyaningsih, Y. Faktor Risiko Kejadian Carpal Tunnel Syndrome (CTS) pada Wanita Pemetik Melati di Desa Karangcengis, Purbalingga. Jurnal Promosi Kesehatan Indonesia. 2008. 3(1): 32.

Kurniawidjaja, M., 2010. Teori dan Aplikasi Kesehatan Kerja. Jakarta: UI Press.

Notoatmodjo, S., 2010. Metodologi Penelitian Kesehatan. Jakarta: Rineke Cipta.

Soehatman, R., 2010. Pedoman Praktis Manajemen Risiko dalam Perspektif K3 OHS Risk Management. Jakarta: Dian Rakyat.

Tony, S., 2013. The Impact of Line Maintenance Mechanics Attitude, Behavior on Aircraft Safety: A Study of Two Aircraft Maintenance in Hong Kong. Journal of Management Research. 5. 133-174.

Undang-Undang Republik Indonesia No. 13 tahun 2003 tentang Ketenagakerjaan. Jakarta: Kementerian Tenaga Kerja.

Wiranatha, I.G., Aryasih, I Gusti Ayu Made., Posmaningsih, D.A.A., 2014. Pengaruh Lama Kontak Hidrogen Peroksida Terhadap Keluhan Subjektif Pengrajin Lontar. Jurnal Kesehatan Lingkungan, 4(1): 62. Tersedia di: http:// poltekkes-denpasar.ac.id/files/JURNAL $\% 20$ KESEHATAN\%20LINGKUNGAN/I\%20 Gede\%20Pandu\%20Wiranatha 1,\%20I\%20 Gusti\%20Ayu\%20Made\%20Aryasih2,.pdf [diakses tanggal 2 Juli 2017]. 